\title{
An Empirical Reflection of Organisational Processes in a Government Department
}

\author{
Chengedzai Mafini
}

Faculty of Management Sciences, Vaal University of Technology, P.Bag X021, Vanderbijpark

Email: chengedzai@hotmail.com

\section{Doi:10.5901/mjss.2014.v5n8p218}

Abstract

The purpose of this study was to explore the underlying factors that influence organisational performance in a government department. A quantitative design using the cross-sectional survey approach was used in which a two-section structured questionnaire was administered to managers and employees of a South African government department. Respondents were recruited using a blend of purposive and convenience sampling methods. Data were analysed using SPSS (Version 21.0). Organisational process factors were extracted using exploratory factor analysis. Four factors; namely, organisational structure, organisational change, organisational teamwork and organisational leadership that influence organisational performance in a government department were extracted. Mean-score ranking of these factors revealed that organisational teamwork exerted the highest impact on organisational performance. The factors identified in this study may be used as reference points in the diagnosis of performance problems in public sector organisations.

Keywords: Process factors, organisational structure, organisational change, organisational teamwork, organisational leadership, government department, South Africa

\section{Introduction}

Since public organisations are complex entities, leading or managing them is challenging, particularly when one intends to enhance their performance. Improvements in performance can only be achieved by understanding both the internal and external dynamics of the organisation (Lin, 2000). In doing so, it has to be appreciated that there is no single universally accepted perspective that captures the entire stream of organisational life and behaviour (Gruchman, 2009). Among the various organisational paradigms that have emerged in recent times is the organisational processes perspective which offers interesting insights that make the subject of organisational performance more comprehensible. As suggested by Mele (2005), organisations are vehicles through which work is coordinated to produce outputs in a stable way across space and time. Moreover, the production of outputs is conducted by manipulating a mishmash of organisational processes (Langley, 2007). In view of this, it is necessary to direct more effort to the subject of process thinking when conducting organisational studies.

The purpose of this study was to explore organisational processes that influence organisational performance in a South African government department. There are several reasons for conducting the study. First, organisational performance in the South African public sector remains depressed as evidenced by the poor quality of service delivery (Nilsson, 2010). This creates an impetus to continue the search for empirically derived solutions to this nagging problem. On the same note, it has been established that the level of performance in an organisation is, among other things, determined by the nature and quality of organisational processes (Hernes, 2007). As such, this study sought to identify those process factors that are instrumental in shaping the level of organisational performance in an organisation, thereby providing a partial solution to performance problems in public organisations. Additionally, there appears to be a paucity of research studies on process factors in the context of developing countries such as South Africa. This study was intended to inhabit this gap. Furthermore, the undercurrents associated with organisational process factors in any setting continue to evolve. This motivates the need for research on a continuous basis, in order to update what is already known on the subject.

\section{Review of Related Literature}

\subsection{Research theory}

The conceptualisation of organisations as a series of processes is linked to a body of theory that is known as the 'process 
perspective', 'process philosophy', 'process metaphysics', or the 'process-based view' (Mwita, 2000). Process thinking is a body of ideas directed at conceptualising the organisation as a process (Koskinen, 2011). Kirby (2005) defines a process as a series of actions, changes or functions that bring about a result. Pearce and Robinson (2009) define organisational processes as an assortment of related, structured activities or tasks that produce a specific service or product (i.e. they serve a particular goal). Process thinking addresses questions about temporary evolving phenomena, which implies that the process perspective is a more dynamic approach to organisational and management issues (Langely \& Tsoukas, 2010). It considers phenomena dynamically in terms of movement, activity, events, change and temporal evolution (Langley, 2007). As such, the process view involves a consideration of how and why things such as people, organisations, rules and norms, evolve over time and space.

As argued by Boyne, Martin and Walker (2009), the organisational processes approach addresses issues related to the formal structure, technical requirements of the organisation and the general sets of principles as the major determinants of organisational performance. It emphasises organisational practices that include formal relations among an organisation's departments, its structural elements such as division of labour, hierarchical authority, rules and decisions that would maximise economic rewards in an organisation (Putu, Mimba, Van Heden \& Tillema, 2007). For example, the manager's role in the hierarchy may influence organisational performance (Hernes, 2007). Likewise, policies and rules enacted and enforced within organisations can have a bearing on the actual performance of the organisation (Garvin, 1998). There are organisations that continue to post poor results despite having impeccably credentialed human talent as well as powerful organisational systems (Koskinen, 2011). In such circumstances one may have to investigate the relationship between the processes that are in place in that organisation and performance of that organisation (Rynes, 2007).

The process perspective on organisations suggests that although change always has primacy, a sense of order can emerge temporarily when distinctions are made between different types of situations (Koskinen, 2011). Organisational life is taken to be ever mutating, and yet the existence of organisations as stable frames of human action and sense-making is not assumed (Hernes, 2010). Therefore, the process-based view of the organisation emphasises elements such as movement, change and transformation over elements such as stability, permanence and order, implying that organisations are not things made but rather processes in the making (Hernes, 2007). The fact that organisations are made up of processes indicates that there is room to positively adjust every stage of the process in order to enhance performance (Robinson, 2006)

\subsection{Classification of Organisational Processes}

Garvin (1998) establishes that there are three separate but related categories of organisational processes, namely: (1) work processes, (2) behavioural processes, and (3) change processes. The work-processes approach has the goal of completing tasks and is premised on the idea that organisations accomplish their work through linked chains of activities cutting across departments and functional groups (Moffett, McAdam \& Parkinson, 2003). Work processes are divided into operational processes (e.g. manufacturing, new-product development, and logistics) and administrative processes (e.g. organisational structure, strategic planning, budgeting, and performance management systems) (Garvin, 1998). Behavioural processes focus on patterns of behaviour inherent in the organisation that exhibit the characteristics of that organisation with examples being decision-making, trust and communication processes (Sher \& Lee, 2004). Examples include teamwork, leadership and organisational learning. Change processes are clearly dynamic and inter-temporal and examples include the organisational life cycle and Darwinian evolution (Škrinjar, Bosilj-Vukšić \& Indihar- Štemberger, 2008).

\subsection{The importance of the organisational processes perspective}

It is important to understand why the process perspective should be adopted and promoted. First, process knowledge is relevant to managerial practice (Moffet et al., 2003). By assuming that organisations are static entities, most traditional cross models of management fail to account for the temporal dynamics that characterise most organisations (Gruchman, 2009). For instance, the finding that one organisation performed better than its competitors does not explain how to transition the competitors to the performance status of a highly performing organisation. The process-based view addresses such issues by explaining the processes that underperforming organisations must engender in order to improve their performance (Meyer, Gaba \& Colwell, 2005). In addition, action under complexity interacts with its context to generate reactions, with unexpected implications that do not exist in most static models (Langley \& Tsoukas, 2010).

Rynes (2007) proposes that process studies that examine how changes in practices are implemented, and how 
their influence spreads and interacts with existing organisational contexts offer a move closer towards a better understanding of how to improve them. This enables organisational leaders to adopt established evidence, based on facts rather than myopic management knowledge in their duties, an aspect that is important especially when one intends to improve performance (Langley, 2007). As observed by Cater and Cater (2009) the use of a fact-based approach to management ensures that the strategies that are initiated are more effective and lead to desired outcomes.

Process conceptualisations are also important because they take the time dimension into account, thereby offering an essential contribution of one's understanding of the world that is not offered by more traditional conceptual models that tend to disregard the element of time completely (Rynes, 2007). This is called the principle of 'comparative statics' as it involves the re-evaluation of quantitative relationships at successive times to provide a better understand various phenomena (Langley, 2007). The understanding of comparative statistics itself is crucial in developing strategies for the improvement of organisational performance (Škrinjar et al., 2008)

Garvin (1998) contends that processes offer a level of analysis which is both convenient and intermediate because they consist of diverse, interlinked tasks. This brings in the needed integration, which ensures that the realities of work practice are linked categorically to the organisation's overall functioning (Ahn \& Chang, 2004). A process lens provides fresh insights into managerial behaviour since it emphasises the interconnections that exist among activities, which shows that seemingly unrelated activities are often part of a single, unfolding sequence. This in turn ensures that managerial work becomes more rational and orderly (Garvin, 1998).

\section{Methodology}

\subsection{Research Design}

The quantitative research design using the cross-sectional survey approach was adopted as the nominal anchor for conducting the empirical part of the present study. The ability to facilitate the collection of data from large groups of respondents with ease, the capability to include a wide variety of variables in the study, the ease of questionnaire construction and administration, the minimum investment to develop and administer, and the simplicity with which associated generalisations can be made (Zikmund, Babin, Carr \& Grifin, 2009), are some of the motivations behind the adoption of the cross-sectional survey approach in this study.

\subsection{Participants and sampling}

For the purposes of this study, two sampling techniques; namely, purposive sampling and convenience sampling were used to recruit 272 employees of a South African government department. The purposive sampling technique was used because it facilitates the selection of those sample elements that can best serve the research purpose (Sun, Wang, Zhang \& Smith, 2008). In the current study, convenience sampling, in which respondents are selected on the premise that they are readily available or easily accessible (Sousa, Zauszniewski \& Musil, 2004) was used as an extension of purposive sampling in the selection of respondents. Use of this combination of sampling techniques ensured that there would be a higher response rate. The sample size used in the present study was determined using Avikaran's (1994) prescription that between 200 and 500 respondents are sufficient when dealing with multivariate statistics such as factor analysis. Therefore, the initial sample size was set at $n=400$ respondents.

\subsection{Measurement Scales and data collection and procedures}

Measurement scales used in the current study were adapted from validated questionnaires used in previous studies. Adaptation of other questionnaires was conducted to ensure that the questionnaire matched the needs of the respondents, location, language, or mode, or any combination of these (Harkness, 2010). As such, a two section questionnaire was developed and subsequently used to collect primary data. Section A of the questionnaire was selfdesigned and measured respondents' demographic information such as gender, age, race and job position. Questions used in Section B elicited information on organisational processes and were adapted from studies conducted by Duncan, Gintei and Swayne (1998:11), Taylor (2000: 111), Rosemann and DeBruin (2005:7), and Hung (2006:23). Notably, the original questions were applied in environments different from that used in the current study. Therefore, the process of adaptation entailed modifying these questions so that they could suit the context of the current study. The modifications included substantive adjustments to such aspects as language used, grammar, as well as the level of difficulty in each question. The questions in Section B were presented in the form of a Likert Scale configuration, anchored by 1 (strongly 
disagree) to 5 (strongly agree). The Likert scale was preferred because it is fairly easy to construct and simplifies data collection and analysis, which made it more appropriate for the purposes of the current survey (Kothari 2009).

Before administering the questionnaires in July 2012, permission to conduct the study as well as ethical clearance were granted by management at the Government organisation. A trained employee in the department was deployed to assist in the data collection process. Ethical considerations such as the participants' right to anonymity, confidentiality, privacy or non-participation, informed consent and protection from discomfort, harm and victimisation were adhered to during the administration of the questionnaire. Out of the 400 questionnaires that were initially distributed, 301 questionnaires were returned. In the screening process, it emerged that 29 questionnaires were either incomplete or had more than one answer on several questions. These were subsequently eliminated, which culminated in the 272 suitable questionnaires that were used in the final data analysis, giving a response rate of 68\%. Since Fincham (2008) recommends a minimum response rate of $60 \%$ in surveys, the response rate obtained in the current study was acceptable as it surpassed the recommended minimum.

\subsection{Data Analysis}

Data analyses were conducted using the Statistical Package of the Social Sciences (SPSS version 21.0). Simple descriptive statistics were employed to analyse the demographic characteristics of the sample. Organisational process factors were identified using exploratory factor analysis. The mean score ranking technique was used to compare the importance of the extracted factors relative to each other.

\section{Research Results}

\subsection{Demographic profile of Respondents}

Table 1 shows the demographic representation of the respondents.

Table 1: Sample demographic characteristics

\begin{tabular}{|lcl|}
\hline Parameter & Frequency & $\%$ \\
\hline Gender & & \\
Male & 150 & 55.15 \\
Female & 122 & 44.85 \\
Total & 272 & 100 \\
Age Group & & \\
$\leqq 25$ & 23 & 8.46 \\
$26-35$ & 135 & 49.63 \\
$36-45$ & 75 & 27.57 \\
$46-55$ & 29 & 10.66 \\
$\geqq 56$ & 10 & 3.68 \\
Total & 272 & 100 \\
Employment Period & & \\
$\leqq 2$ years & 111 & 40.81 \\
$2-5$ years & 89 & 32.72 \\
6-9 years & 39 & 14.34 \\
\9years & 33 & 12.13 \\
Total & 272 & 100 \\
Type of Employment & & \\
Permanent & 223 & 81.99 \\
Contract & 38 & 13.97 \\
Part Time & 11 & 4.04 \\
Total & 272 & 100 \\
Academic Qualifications & & \\
Matric & 15 & 5.51 \\
Certificate & 29 & 10.66 \\
Diploma & 69 & 25.37 \\
Degree & 117 & 43.01 \\
Postgraduate Degree & 40 & 14.71 \\
\hline
\end{tabular}




\begin{tabular}{|lll|}
\hline \multicolumn{2}{l}{ Other (e.g. professional qualifications)2 } & 0.74 \\
Total & 272 & 100 \\
Current Position & & \\
Executive manager & 4 & 1.47 \\
Senior manager & 18 & 6.62 \\
Middle manager & 24 & 8.82 \\
Line manager & 48 & 17.65 \\
Specialist staff & 74 & 27.21 \\
Clerical/ Administrative & 70 & 25.74 \\
Other (e.g. general worker) & 34 & 12.50 \\
Total & 272 & 100 \\
\hline
\end{tabular}

In terms of the demographic profile of the respondents, $55 \%$ (150) of the respondents were male and $45 \%$ (122) were female. Approximately $58 \%(185)$ of the respondents were aged below 35 years and $74 \%(200)$ of the respondents had been employed in the department for periods less than 5 years. With regard to the type of employment, $82 \%(223)$ of the respondents were under permanent employment within the department. In terms of the qualifications held, $43 \%$ (117) of the respondents were holders of a first degree and approximately $15 \%$ (40) of the respondents were holders of a postgraduate degree. Furthermore, 1.5\% (4) of the respondents were executive managers, $7 \%$ (18) were senior managers, 9\% (24) were middle managers, 18\% (48) were line managers, 27\% (74) were specialist staff, 26\% (70) were clerical or administrative staff and 13\% (34) occupied other auxiliary positions such as internships, security and general work.

\subsection{Validity and reliability}

In the current study, Alumran, Hou and Hurst's (2012) conceptualisation of validity as the degree to which evidence and theory support the interpretations of test scores entailed by proposed uses of tests was espoused. Content and face validity were established by requesting a panel of experts consisting of three senior faculty members at a South African university of technology, who are experienced researchers in the discipline of strategic management, to assess the suitability survey items. Additionally, the questionnaire was pre-tested with a conveniently selected sample of respondents. Using feedback from the experts and the pretest, changes were made to the questionnaire regarding the deletion of items, addition of items, rewording and rephrasing of questions. Construct validity was assessed through the reliabilities of the factors (refer to Table 3) and was measured using the Cronbach alpha coefficient. The standardised Cronbach alpha reliabilities of the five factors were considered to be satisfactory because they were greater than the recommended 0.7 (Malhotra 2011). Furthermore, construct validity was assessed through exploratory factor analysis (EFA). The results indicated that there were no cross-loadings within constructs, leading to the extraction of four organisational process factors.

\subsection{Exploratory factor analysis}

In the present study, exploratory factor analysis using the Principal Components Analysis (CPA) method and Varimax rotation (Conway \& Huffcutt, 2003) was used to identify organisational process factors. The scale was purified by excluding low factor loadings, cross-loadings and low communalities in order to enhance the "interpretability of the factor structure" (Malhotra 2010:643). The minimum cut-off point used on the variable loadings was 0.50 , as recommended by Hair et al. (2010). Johnson and Wichern's (2002) prescription that it is important to calculate a Bartlett's test of Sphericity and the Kaiser-Meyer-Olkin (KMO) measure of sampling adequacy in order to establish whether the captured data are suitable for exploratory factor analysis, was embraced and implemented in this study. The results of these tests are reported in Table 2.

Table 2: KMO and Bartlett's Tests Results for Organisational Processes

\begin{tabular}{|l|c|c|}
\hline \multicolumn{2}{|c|}{ Kaiser-Meyer-Olkin Measure of Sampling Adequacy. } & 0.792 \\
\hline \multirow{3}{*}{ Bartlett's Test of Sphericity } & Approx. Chi-Square & 3345.162 \\
\cline { 2 - 3 } & Df & 509 \\
\cline { 2 - 3 } & Sig. & 0.001 \\
\hline
\end{tabular}


As unveiled in Table 2, the Kaiser-Meyer-Olkin (KMO) measure of sampling adequacy was calculated at $0.792(>0.50)$ and a Bartlett's Test of Sphericity at (Sig = 0.001) supported by an approximated Chi-square of 3345.162 at 509 degrees of freedom (df). This result indicated that the captured data under organisational processes were suitable for factor analysis.

\subsection{Exploratory factor analysis for organisational processes}

Four factors were extracted through the exploratory factor analysis procedure. The rotated factor loading matrix illustrating the resultant factors, eigen values, percentage of variance explained and reliabilities is provided in Table 3.

Table 3: Rotated Component Matrix: Organisational Processes

\begin{tabular}{|c|c|c|c|c|c|}
\hline \multirow{2}{*}{ Item Code } & Factors and variable descriptions: Organisational Processes & Factor 1 & Factor 2 & Factor 3 & Factor 4 \\
\hline & \multicolumn{5}{|l|}{ Factor 1: Organisational Structure } \\
\hline E1 & The goals of this organisation are clearly stated & 0.644 & 0.151 & 0.143 & 0.183 \\
\hline E2 & The division of labour of this organisation is flexible & 0.533 & 0.324 & 0.249 & 0.067 \\
\hline E3 & The division of labour of this organisation is flexible & 0.773 & 0.257 & 0.206 & 0.056 \\
\hline E4 & The manner in which tasks are divided is a logical one & 0.743 & 0.294 & 0.258 & -0.074 \\
\hline E5 & The structure of my work unit is well designed & 0.645 & 0.369 & 0.239 & -0.093 \\
\hline E6 & The division of labour in this organisation actually helps it to achieve its goals & 0.608 & 0.250 & 0.235 & 0.059 \\
\hline \multicolumn{6}{|c|}{ Factor 2: Organisational Change } \\
\hline E7 & There are many changes taking place in this organisation & 0.201 & 0.614 & 0.049 & 0.218 \\
\hline E8 & Occasionally, I am allowed to change things around my job & -0.073 & 0.820 & 0.122 & 0.042 \\
\hline E9 & This organisation has the ability to change & 0.049 & 0.577 & 0.387 & 0.324 \\
\hline \multicolumn{6}{|c|}{ Factor 3: Organisational Teamwork } \\
\hline E10 & I can always talk with workmates if I have a work-related problem & 0.277 & 0.174 & 0.744 & 0.048 \\
\hline E11 & My relationships with members of my work group are friendly and professional & 0.186 & -0.261 & 0.846 & -0.037 \\
\hline E12 & I have established the relationships that I need to do my work properly & 0.244 & 0.269 & 0.716 & 0.242 \\
\hline E13 & Other work units are helpful to my work unit whenever assistance is required & 0.298 & 0.224 & 0.530 & 0.306 \\
\hline E14 & There is no evidence of unresolved conflict in the organisation & 0.427 & 0.308 & 0.646 & 0.481 \\
\hline \multicolumn{6}{|c|}{ Factor 4: Organisational Leadership } \\
\hline E15 & I feel good to be around my leaders & 0.271 & 0.193 & 0.286 & 0.756 \\
\hline E16 & My leaders enable me to think about old problems in new ways & 0.272 & 0.203 & 0.185 & 0.721 \\
\hline E7 & I have faith in my leaders & 0.351 & 0.044 & 0.238 & 0.812 \\
\hline E18 & My leaders give me positive feedback on my work & 0.256 & 0.025 & 0.209 & 0.813 \\
\hline E19 & My leaders reward me when I do well & 0.150 & -0.101 & 0.089 & 0.780 \\
\hline E20 & My leaders give me personal attention when I feel rejected & 0.253 & -0.012 & 0.168 & 0.807 \\
\hline \multicolumn{2}{|l|}{ Eigenvalue } & 4.745 & 4.517 & 2.692 & 1.362 \\
\hline \multicolumn{2}{|c|}{$\%$ of variance explained } & 23.724 & 22.584 & 13.460 & 6.810 \\
\hline \multicolumn{2}{|c|}{ Cumulative $\%$ of variance explained } & 23.724 & 46.308 & 59.768 & 66.579 \\
\hline \multicolumn{2}{|c|}{ Reliabilities } & 0.803 & 0.771 & 0.782 & 0.822 \\
\hline \multicolumn{6}{|c|}{$\begin{array}{l}\text { Extraction Method: Principal Component Analysis. } \\
\text { Rotation Method: Varimax with Kaiser Normalization. }{ }^{a} \\
\text { a. } 4 \text { components extracted }\end{array}$} \\
\hline
\end{tabular}

In analysing the responses of managers and employees of the government department regarding organisational processes, four factors; specifically, organisational structure, organisational change, organisational teamwork and organisational leadership were identified through the exploratory factor analysis procedure. These factors accounted for approximately $66 \%$ of the variance, which lies within Malhotra and Birks's (2003) recommendation that the cumulative percentage of variance extracted by the factors should be at least $60 \%$. The four factors also showed reliabilities which were above the 0.70 standard prescribed by Hair et al. (2010), which signals that the scales had acceptable levels of internal consistency.

\subsection{Mean scores for organisational processes subscales}

Table 4 provides an indication of the means, medians standard deviation and mean score ranking of each factor. 
Table 4: Factor, number of items, mean and standard deviation for the organisational processes sub-scales

\begin{tabular}{lcccc}
\hline \multicolumn{1}{c}{ Factor } & Number of items & Summated Mean Scores & Standard Deviation & Mean Score Ranking \\
\hline Organisational Structure & 6 & 4.535 & 0.811 & 2 \\
Organisational Change & 3 & 4.523 & 0.737 & 3 \\
Organisational Teamwork & 5 & 4.657 & 0.713 & 1 \\
Organisational Leadership & 6 & 4.274 & 0.958 & 4 \\
\hline
\end{tabular}

Table 4 reveals that organisational teamwork $(\bar{x}=4.657)$ contributed most to organisational performance in the government department, followed by organisational structure $(\bar{x}=4.535)$, organisational change $(\bar{x}=4.523)$, while organisational leadership ( $\bar{x}=4.274$ ) contributed the least. The fact that the mean scores for the four process factors were between the 'agree' and 'strongly agree' positions on the Likert scale suggests that respondents perceived that the government department's performance with regard to these factors was satisfactory. However, in terms of the organisational leadership factor, a possible explanation for the result could be that improvements are necessary in the leadership styles used within the department. There could be gaps in areas such as giving personal attention to subordinates, rewarding and giving positive feedback to subordinates, and motivating or inspiring subordinates to excel, which were examined in the study. As suggested by a number of management scientists, (Puspanathan \& Lin, 2008; Hè, 2009; Wang, Chich-Jen \& Mei-Ling 2010), leadership styles used by organisational leaders impact strongly on organisational performance. Performance of the government department could therefore be enhanced through positive structural adjustments to the leadership styles used by management in the department. The standard deviation scores which are all below a whole number also depict that there is more certainty within the results of the study.

\section{Discussion}

Factor 1, labelled as organisational structure, consisted of six items and accounted for $24 \%$ of the total variance explained. The factor attained a Cronbach alpha of 0.803 , which indicates high internal consistency. Organisational structure is concerned with the hierarchy of the organisation and how the components of this hierarchy work together to achieve the objectives of the organisation (Banai \& Reisel, 2007). Most of the available literature seems to suggest that there exists a profound relationship between structure and organisational performance. For instance, Schminke, Ambrose and Cropanzano (2000) argue that a decentralised organisational structure is conducive to the improvement of organisational effectiveness and performance. Decentralised structures also encourage more effective communication in addition to increasing employee satisfaction and motivation (Zheng, Yang, \& McLean, 2010). This could be attributed to the fact that in less centralised environments, the free flow of lateral and vertical communication is encouraged (Shafritz, Ott \& Jang, 2005). Decentralised organisational structures also have a positive impact on other areas that include decision-making, responsiveness to market conditions and encouraging the adoption of innovation and higher levels of creativity (Schminke, Ambrose \& Cropanzano, 2000). Conversely, high centralisation stifles interactions among organisational members (Gold, Malhotra \& Segars, 2001), reduces the opportunity for individual growth and advancement (Zheng et al., 2010) and inhibits innovative solutions to problems (Schminke et al., 2000). Therefore, managers are encouraged to ensure that they design lean, decentralised organisational structures in order to stimulate performance in their various organisations (Tsai \& Huang, 2008).

Factor 2, labelled organisational change, consisted of three items that accounted for $23 \%$ of the total variance explained. The factor also had a Cronbach alpha of 0.771 , which indicates acceptable reliability. Organisational change is concerned with processes in which the working methods or aims of an organisation are altered, for example in order to develop and deal with new situations (Liu \& Perrewé, 2005). Literature is accessible that attempts to explain the possible effects of organisational change on organisational performance. For instance, Judge and Elenkov (2005) found that the organisation's capacity for change influences an environmental performance in that the higher that capacity, the more the organisation is able to perform in its operational environment. Properly implemented organisational change also facilitates process improvement, which in turn has a stimulus effect on organisational performance (Lee \& Ahn, 2008). Nordin (2011) also found that an organisation's preparedness for change is explained by factors such as emotional intelligence, organisational commitment and transactional leadership behaviour. This suggests that an organisation's ability to change can only be enhanced when the identified factors are optimised (Liu \& Perrewé, 2005). Tsamenyi, Onumah and TettehKumah (2010) observed that organisational changes in various levels of the organisation positively influenced the postprivatisation performance of specific companies in Ghana while Palcic and Reeves (2010) also found that organisational changes had impacted positively on the post-privatisation performance of Ireland's national telecommunications operator, 
Telecom Éireann. Therefore, on the overall, organisational change remains a strategic and fundamental process that should be expedited in order to enhance overall performance of the organisation (Diefenbach, 2005).

Factor 3, labelled as organisational teamwork, consisted of five items that accounted for $13 \%$ of the variance. This factor attained a Cronbach alpha of 0.782 , which indicates acceptable internal consistency. Team processes are concerned with the prevalence of joint actions by a group of people, in which each individual subordinates his or her individual interests to those of the group (Acuna, Gomez \& Juristo, 2009). Teams are also formed when individuals with a common taste, preference, liking, and attitude come and work together for a common goal (Bandow, 2001). Every employee is dependent on his fellow employees to work together and contribute efficiently to the organisation (Burke et al., 2006). It has been observed that the outcome is far better when employees work in a team rather than individually, as every individual can contribute in his/her best possible way (Derby \& Larsen, 2006). Teamwork is also essential in organisations for better output and a better bonding among employees since tasks are accomplished at a faster pace when they are done by a team rather than an individual (Salas, Sims \& Burke, 2005). There is usually healthy competition among team members in addition to the improvement of relations among employees as well as the platform for team members to gain from each other (Morgan, 2010:97). Organisational teamwork therefore occupies an important place as an essential element for organisational success and must be encouraged if organisational goals are to be accomplished (Salas et al., 2005).

Factor 4, labelled as organisational leadership, consisted of six items (E15, E16, E17, E18, E19 \& E20) that accounted for $7 \%$ of the total variance explained. This factor attained a high Cronbach alpha of 0.822 which indicates high reliability. Leadership is concerned with the extent to which authorities are able to inspire and motivate their subordinates towards the attainment of a common goal (Whittington, Goodwin \& Murray, 2004). Research has established that there is a positive relationship between positive leadership and performance (Elenkov, 2002). Leadership, which involves both visionary and charismatic elements, is associated with higher performance, both for individuals, groups and organisations across cultures and contexts (Sashkin \& Sashkin, 2003). Leadership behaviours cascade down through the various organisational levels and have the effect of raising the degree of performance at every level. When employees are subjected to supportive leadership, their consciousness about the importance and value of goals is likely to be enhanced together with the ways that the employees can use to attain these organisational goals (Dasborough, Ashkanasy, Tee \& Tse, 2009). This implies the leaders and followers will identify with the organisation's goals and work with a common purpose toward their attainment (Hancott, 2005). Huang (2006) maintains that leadership has a positive correlation with organisational performance. It can therefore be noted that without proper leadership, organisations are bound to fail (Brown \& Treviño, 2006).

\section{Conclusions and Managerial Implications}

The purpose of this study was to identify organisational process factors influencing organisational performance in a South Africa government department. Application of the exploratory factor analysis procedure led to the extraction of four factors; namely, organisational structure, organisational change, organisational teamwork and organisational leadership. The mean score ranking approach was used to determine the strength of each organisational process factor relative to the others. The means of the four factors were all slanting towards the 'strongly agree' position on the scale, showing that all four factors were regarded as important by respondents. Organisational teamwork emerged as the most important factor in influencing organisational performance, with organisational structure coming second, organisational change coming third and organisational leadership occupying the least position.

The study identified four organisational processes which are key determinants of organisational performance in a government department. To a certain extent, this implies that organisational performance can be increased by enhancing each of these four process factors. To reinforce the effectiveness of all process factors identified in the study, management in government departments should initiate and implement organisational development programmes on a continuous basis. The prime purpose of organisational development is to improve the organisation's capacity to handle its internal and external functioning and relationships (Bradford \& Burke, 2005). This would include such interventions as improved interpersonal and group processes, more effective communication, enhanced ability to cope with organisational problems of all kinds, more effective decision processes, more appropriate leadership styles, improved skill in dealing with destructive conflict, and higher levels of trust and cooperation among organisational members (de-Kler, 2007). According to Western (2010) there are many organisational development interventions that are important in streamlining systems and processes range from those intended to improve the effectiveness of individuals through those designed to deal with teams and groups, intergroup relations, as well as the total organisation. Interventions are also available that place emphasis on task issues (what people do), and those that place emphasis on process issues (how people go about 
doing it).

Business process management (BPM) could also be adopted as a vital tool to update all organisational processes. It has been referred to as a "holistic management" approach to aligning an organisation's business processes with the wants and needs of clients. It promotes business effectiveness and efficiency while striving for innovation, flexibility, and integration with technology (vom Brocke \& Rosemann, 2010). BPM attempts to improve processes continuously. It can therefore be described as a process optimisation strategy. BPM also enables organisations to be more efficient, more effective and more capable of change than a functionally focused, traditional hierarchical management approach. Adoption of BPM typically leads to higher customer satisfaction, product quality, delivery speed and time-to-market speed (Kohlbacher, 2009). By implementing BPM programmes, the efficiency and overall performance of organisations also improves significantly (Vera \& Kuntz, 2007).

\section{Limitations and Implications for Further Research}

The results of this study should be considered within the light of its limitations. Firstly, the study was conducted using a small sample size of 272 civil servants who were based in the Gauteng Province of South Africa. In line with this, the results of the study may not be easily applicable in other contexts and regions. To address this limitation, future studies could be conducted using an amplified sample size drawn from a larger geo-spatial context. Secondly, the use of the nonprobability convenience sampling technique naturally enhanced the study's vulnerability to sampling bias (Whitely \& Kite, 2009). With this in mind, it would be interesting to conduct similar studies using samples that are recruited using probability sampling techniques such as simple random or stratified samples. Additionally, it would be interesting to examine the relationship between each of the four process factors and various socio-demographic variables such as age, gender and educational levels of respondents. The results could be more informative if the views of both internal and external stakeholders were included and compared. This presents the need for conducting similar studies using perceptions of other external stakeholders such as the clients. The importance of additional process factors that influence organisational performance could also be examined. This could lead to the uncovering of any omissions within the dimensions tested in this study. Furthermore, since the current study focused on the organisational processesperformance nexus within a public organisation, comparative investigations could also be conducted in other environments such as private enterprises and not-for-profit organisations.

\section{References}

Acuna, S.T., Gomez, M. \& Juristo, N. (2009). How do personality team processes and task characteristics relate to job satisfaction and software quality? Information and Software Technology, 51(3):627-639.

Alumran, A., Hou, X. \& Hurst, C. (2012). Validity and reliability of instruments designed to measure factors influencing the overuse of antibiotics. Journal of Infection and Public Health, 5(3):221-232.

Avikaran, N. K. (1994). Developing an instrument to measure customer service quality in branch banking. International Journal of Bank Marketing, 12(6):10-18.

Ahn, J.H. \& Chang, S.G. (2004). Assessing the contribution of knowledge to business performance: the KP3 methodology. Decision Support Systems, 36(4): 403-416.

Banai, M. \& Reisel, W.D. (2007). The influence of supportive leadership and job characteristics on work alienation: a six-country investigation. Journal of World Business, 42: 463-476.

Bandow, D. (2001). Time to create sound teamwork. The Journal for Quality and Participation, 24(2): 41-47.

Boyne, G., Martin, S. \& Walker, R. (2009). Explicit reforms, implicit theories and public service improvement: the case of best value. Cardiff University, Local \& Regional Government Research Unit, Discussion Paper 4.

Bradford, D.L. \& Burke, W.W. (2005). Organisation development. San Francisco: Pfeiffer.

Brown, M.E. \& Treviño, L.K. (2006). Ethical leadership: a review and future directions. The Leadership Quarterly, 17: 595-616.

Burke, C.S., Stagl, K.C., Klein, C., Goodwin, G.F., Salas, E. \& Halpin, S.A. (2006). What type of leadership behaviors are functional in teams? a meta-analysis. Leadership, 17(3): 288-307.

Čater, T. \& Čater, B. (2009). Tangible resources as antecedents of a company's competitive advantage and performance. Journal for East European Management Studies, 14(2): 186-209.

Conway, J. M. \& Huffcutt, A. I. (2003). A review and evaluaton of exploratory factor analysis practices in organisational research. Organisational Research Methods, 6(2): 147-168.

Dasborough, M.T., Ashkanasy, N.M., Tee, Y.J. \& Tse, H.M. (2009). What goes around comes around: how meso-level negative emotional contagion can ultimately

determine organizational attitudes toward leaders. The Leadership Quarterly, 20: 571-585.

De-Kler, M. (2007). Healing emotional trauma in organisations: an O.D. framework and case study. Organisational Development Journal, 25(2): 49-56. 
Derby, E. \& Larsen, D. (2006). Agile retrospectives: making good teams great. London: Pragmatic Bookshelf.

Duncan, J., Gintei, P.M. \& Swayne, L.E. (1998). Competitive advantage and internal organizational assessment. Academy of Management Executive, 12(3): 6-16.

Diefenbach, T. (2007). The managerialistic ideology of organisational change management. Journal of Organizational Change Management, 20(1): $126-144$

Elenkov, D.S. (2002). Effects of leadership on organisational performance in Russian companies. Journal of Business Research, 55 : 467-480.

Fincham, J. E. (2008). Response rates and responsiveness for surveys, standards, and the journal. American Journal of Pharmaceutical Education, 72(2): 43-55.

Garvin, D.A. (1998). The processes of organisation and management. Sloan Management Review, 39(4): 33-50.

Gold, A. H, Malhotra, A. \& Segars, A.H. (2001). Knowledge management: an organisational capabilities perspective. Journal of Management Information Systems, 18(1):185-214.

Gruchman, G.B. (2009). The process-based view of a company: principles and applications- part 2. Business Process Trends, February.

Hair, J.F., Black, B., Babin, B., Anderson, R.E., Tatham, R.L. \& Black, W.C. (2010). Multivariate data analysis: a global perspective. NY: Pearson Education Inc.

Hancott, D.E. (2005). The relationship between transformational leadership and organisational performance in the largest public companies in Canada. Unpublished doctoral thesis, Capella University, Canada.

Harkness, J. (2010). Cross-cultural survey guidelines. [online]. Available at: <http://ccsg.isr.umich.edu/pdf/07AdaptationNov2010.pdf>. Accessed: 22/06/2012

He, Z.Y. (2009). Research on the structural relationship of primary school teachers in the teacher's beliefs, leadership behavior, classroom management strategies and classroom management performance. Journal of National Taichung University, 23(1): 99127.

Hernes, T. (2007). Understanding organisation as a process: theory for a tangled world. London: Routledge.

Hernes, T. (2010). Actor-network theory, Callon's scallops, and process-based organisation studies. In: Hernes, T., Maitlis, S. (Eds.), Process, sensemaking \& organizing. Oxford University Press, Oxford, pp. 161-184.

Huang, L.S. (2006). Transformational leadership has effect on organisational performance: the organisational culture as an intermediary variable. Unpublished Master's Thesis, National Taipei University, Taipei, Taiwan.

Johnson, R. A. \& Wichern, D.W. (2002). Applied multivariate statistical analysis. Upper Saddle River, New Jersey: Prentice Hall.

Judge, W.Q. \& Elenkov, D. (2005). Organisational capacity for change and environmental performance: an empirical assessment of Bulgarian firms. Journal of Business Research, 58 (7): 893-901.

Kirby, J. (2005). Towards a theory of high performance. Boston, MA: Harvard.

Kohlbacher, M. (2009). The effects of process orientation on customer satisfaction, product quality and time-based performance. Paper presented at the 29th International Conference of the Strategic Management Society, Washington DC, October 11-14.

Koskinen, K. U. (2011). Problem absorption as an organisational learning mechanism in project-based companies: process thinking perspective. International Journal of Project Management, 22(2): 38-51.

Kothari, C. R. (2009). Research methodology: Methods and techniques. $2^{\text {nd }}$ ed. New Delhi: New Age International.

Langley, A. (2007). Process thinking in strategic organisation. Strategic Organisation, 5(3): 271-282.

Langley, A. \& Tsoukas, H. (2010). Perspectives in process organisation studies. Oxford, UK: Oxford University Press.

Lee, S. \& Ahn, H. (2008). Assessment of process improvement from organisational change. Information \& Management, 45(5): 270-280.

Lin, Z.(2000). Organizational restructuring and the impact of knowledge transfer. The Journal of Mathematical Sociology, 24(2): 129-149.

Liu, Y. \& Perrewé. P.L. (2005). Another look at the role of emotion in the organizational change: a process model. Human Resource Management. 15(4): 263-280.

Malhotra, N. K. (2011). Basic marketing research. New Jersey: Prentice Hall.

Malhotra. N. K. \& Birks, D. F. (2003). Marketing research: an applied approach. 2nd edition. London: Prentice-Hall.

Malhotra, N.K. (2010). Marketing research: An applied orientation. $6^{\text {th }}$ edition. New Jersey: Prentice-Hall

Melé, D. (2005). Exploring the principle of subsidiarity in organisational forms. Journal of Business Ethics, 60(3): 293-305.

Meyer, A. D., Gaba, V. \& Colwell, K. (2005). Organizing far from equilibrium: non-linear change in organisational forms. Organisation Science, 16(5): 456-73.

Moffett, S., McAdam, R. \& Parkinson, S. (2003). An empirical analysis of knowledge management applications. Journal of Knowledge Management, 7(3): 6-26.

Morgan, G. (2010). Images of organizations. Thousand Oaks, CA: SAGE publications.

Mwita, T.I. (2000). Performance management model: a systems-based approach to public service quality. International Journal of Public Sector Management, 13(1):10-37.

Nilsson, J. (2010). What's the problem? local officials' conceptions of weaknesses in their municipalities' crisis management capabilities. Journal of Contingencies and Crisis Management, 18(2): 83-95.

Nordin, N. (2011). The influence of emotional intelligence, leadership behaviour and organisational commitment on organisational readiness for change in higher learning institution. Procedia - Social and Behavioral Sciences, 29: 129-138.

Palcic, D. \& Reeves, E. (2010). Organisational status, change and performance: the case of Ireland's national telecommunications operator. Telecommunications Policy, 34 (5/6): 299-308.

Pearce, J.A. \& Robinson, R.B. (2009). Strategic management: formulation, implementation and control. 11'th ed. Singapore: McGraw-Hill. 
Puspanathan, M. \& Lin, A. (2008). Leadership style and organisational performance in family owned small scale manufacturing industries in Sri Lanka. Paper presented at the International Colloquium on Business \& Management. University of Sri Jayewardenepura, Sri Lanka on March 272008.

Putu, N.I., Mimba, S.H., Van Heden, J. \& Tillema, S. (2007). Public sector performance measurement in developing countries: a literature review and research agenda. Journal of Accounting and Organisational Change, 3(3):16-17.

Robinson, H.S. (2006). STEPS: a knowledge management maturity roadmap for corporate sustainability. Business Process Management Journal, 12(6): 793-808.

Rosemann, M. \& Debruin, T. (2005). Application of a holistic model for determining BPM maturity. [online] Available at:<www.bptrends.com/publicationfiles/02\%2D05\%20WP\%20Application\%20of\%20a\%20Holistic\%20Model\%2D\%20Rosemann \%2DBruin\%20\%2D\%E2\%80\%A6\%2Epdf>. Accessed: 20/06/ 2013.

Rynes, S.L. (2007). Editor's foreword: tackling the "great divide" between research production and dissemination in human resource management. Academy of Management Journal, 50(3): 985-986.

Salas, E., Sims, D.E. \& Burke, C.S. (2005). Is there a "big five" in teamwork? Small Group Research, 36(5): 555-599.

Sashkin, M. \& Sashkin, M.G. (2003). Leadership that matters. the critical factors for making a difference in people's lives and organisations' success, San Francisco: Berrett-Koehler Publishers.

Shafritz, J.M., Ott, J.S. \& Jang, Y.S. (2005). Classics of organization theory. $6^{\text {th }}$ ed. Belmont, CA: Thomson Wadsworth.

Schminke, M., Ambrose, M.L. \& Cropanzano, R.S. (2000). The effect of organisational structure on perceptions of procedural fairness. Journal of Applied Psychology, 85: 294-304.

Sher, P.J. \& Lee, V.C. (2004). Information technology as a facilitator for enhancing dynamic capabilities through knowledge management. Information \& Management, 41(8): 933-945.

Škrinjar, R., Bosilj- Vukšić, V. \& Indihar Štemberger, M. (2008). The impact of business process orientation on financial and non-financial performance. Business Process Management Journal, 14(5): 738-754.

Sousa, V. D., Zauszniewski, J.A. \& Musil, C.M. (2004). How to determine whether a convenience sample represents the population. Applied Nursing Research, 17 (2):130-133.

Sun, Y., Wang, H., Zhang, J. \& Smith, J.W. (2008). Probabilistic judgment on a coarser scale. Cognitive Systems Research, 9(4): 161172.

Taylor, W. (2000). Facts, myths and monsters: understanding the principles of good governance. The International Journal of Public Sector Management, 13 (2): 108-24.

Tsai, M.T. \& Huang, C.C. (2008). The relationship among ethical climate types, facets of job satisfaction, and the three components of organizational commitment: a study of nurses in Taiwan, Journal of Business Ethics, 80(3): 565-581.

Tsamenyi, M., Onumah, J. \& Tetteh-Kumah, E. (2010). Post-privatization performance and organisational changes: case studies from Ghana. Critical Perspectives on Accounting, 21(5): 428-442.

Vera, D. \& Crossan, M. (2004). Strategic leadership and organizational learning. Academy of Management Review, 29(2): $222-240$.

Vom-Brocke, J. \& Rosemann, M. (2010). Handbook on business process management: strategic alignment, governance, people and culture. International Handbooks on Information Systems. Berlin: Springer.

Wang, F., Chich-Jen, S. \& Mei-Ling, T. (2010). Effect of leadership style on organisational performance as viewed from human resource management strategy. Journal of Business Management, 4(18): 3924-3936.

Western, S. (2010). What do we mean by organisational development? Krakow: Advisio Press.

Whitley, B.E. \& Kite, M.E. (2009). The psychology of prejudice and discrimination. Hampshire: Cengage Learning.

Whittington, J.L., Goodwin, V.L. \& Murray, B. (2004). Transformational leadership, goal difficulty and job design: independent and interactive effects on employee outcomes. The Leadership Quarterly, 15: 593-606.

Zheng, W., Yang, B. \& McLean, G. N. (2010). Linking organisational culture, structure, strategy, and organisational effectiveness: mediating role of knowledge management. Journal of Business Research, 63(7): 763-771.

Zikmund, M., Babin, B.J., Carr, J.C. \& Griffin, M. (2013). Business research methods. $8^{\text {th }}$ ed. Mason: South Western. 